\title{
Teff (Eragrostis Abyssinica) and Teff Based Fermented Cereals: Review Article
}

\author{
Melaku Tafese Awulachew \\ Department of Food Science and Nutrition Research Process, Ethiopian Institute of Agricultural Research, Kulumsa Agricultural Research \\ Center, Assela, Ethiopia
}

Email address:

Melakutafese12@gmail.com

To cite this article:

Melaku Tafese Awulachew. Teff (Eragrostis Abyssinica) and Teff Based Fermented Cereals: Review Article. Journal of Health and Environmental Research. Vol. 6, No. 1, 2020, pp. 1-9. doi: 10.11648/j.jher.20200601.11

Received: August 19, 2019; Accepted: October 12, 2019; Published: April 8, 2020

\begin{abstract}
Nutritional quality of food is the most important parameter for maintaining human health and complete physical well-being. Since nutritional well-being is the driving force for development and maximization of human genetic potential. Dietary quality of food should be taken into consideration for maintaining human health and fitness to solve the problem of deep rooted malnutrition. Diversification of food production must be encouraged both at national and household level with their increasing yields and techniques. Hence the aim of this review was to assess the opportunities of teff nutrient profiles and teff based fermented cereals. Teff is a reliable and low risk cereal that grows on a wider ecology under moisture stress and waterlogged areas with few plant diseases and grain storage pest problems. Processing of teff for different foods is usually done by traditional ways and is mostly limited to the household level. Processing of the grain for different commercial foods is needed to promote worldwide teff utilization. Teff grain nutrients are promising and it is also an excellent gluten free alternative for people with celiac disease and other gluten allergy. The search for new gluten-free brewing materials is still in its infancy and researchers in this field of study are continuously researching on the malting, mashing, fermentation conditions and other aspects of teff so as to use it as a raw material for gluten-free beer, functional beverages and other gluten-free foods. Teff flour is used extensively in Ethiopia to make injera, a soft flatbread prepared from slightly fermented batter, and the grains are also used in stews and porridges. Teff has increased in popularity as a gluten-free health food in developed countries and has potential as an alternative food crop. In some places the plant is also grown as forage or hay crop, and the stalks are commonly fed to livestock postharvest.
\end{abstract}

Keywords: Nutrient Composition of Teff, Common Teff Based Fermented Cereals, Wheat, Maize, Sorghum, Fermentation

\section{Introduction}

Teff Eragrostis abyssinica (Eragrostis tef), sometimes spelled tef, annual cereal grass (family Poaceae), grown for its tiny nutritious seeds. Teff is native to Ethiopia where it is a staple food crop to millions of people. Teff is a tufted or bunching grass with thin narrow stems and a broad crown. The shallow fibrous roots form a massive root system, and the plant is resistant to both drought and water logging. The self-pollinating flowers are borne in open panicles and produce seeds that range in colour from white to deep red-brown. Teff seeds are among the smallest of all cereal grains, usually measuring less than 1 $\mathrm{mm}(0.04 \mathrm{inch})$ in diameter. Teff utilizes a photosynthetic pathway known as $\mathrm{C}_{4}$ carbon fixation, which largely prevents photorespiration and thus contributes to the plant's drought tolerance.

Teff grain does not contain gluten and is an increasingly important dietary component for individuals who suffer from gluten intolerance [1]. Despite its nutritional and health benefit teff has relatively high concentration of phytic acid, an anti-nutritional factor, which can compromise the bioavailability of vitamins and minerals. Furthermore, due to the high and increasing cost of teff injera made from teff alone is limited to few segment of the society in the country. Therefore, teff is often blended with cheaper cereals to make Injera. Such blends have organoleptic and nutritional implications which is not an easy task to achieve though. Different flour blends affect the fermentation kinetics and nutritional quality of Injera [2]. Even if teff has commonly 
been used by most Ethiopians to prepare Injera, other cereals such as sorghum, millet, barley and maize are also utilized for such purpose especially in the rural communities. In this review, the nutrient composition, physiochemical characteristics and potential health benefits that could be associated with higher consumption of teff and teff based fermented cereals are highlighted.

\section{Material and Methods}

This literature review was formulated through literature searches using Science direct. The following keywords were used: "Nutrient composition of teff, common Teff based fermented cereals, Wheat, maize, sorghum, fermentation ". The logical term operant and was used in the search of items to match keywords. Also this article review researches on teff, evaluate its suitability for different food applications, and give direction for further research on its applications for gluten free food market.

\subsection{Basic of Teff Grain}

The chemical composition of teff is not far from those of other cereals, nonetheless the micro-and macronutrients level of grain teff is apparently higher than that of barley, wheat and sorghum [3] and therefore the nutrient composition of grain teff indicates that it has good potential to be used in foods and beverages worldwide. The amino acid composition of grain teff is reported to be comparable to that of egg protein, except for its lower lysine content [4]. Teff flour has high water absorption capacity which is related to the higher degree of swelling of the teff starches, that have a small and uniform granule size, hence, providing larger surface area and thus higher water absorption [3, 4]. Teff starch has slow retrogradation tendency [3] hence, it could have a potentially positive impact on shelf life of baked products. Teff is high in protein, carbohydrates, and fiber. The protein composition offers an excellent balance among the essential amino acids.

\subsection{Food Formulation Based on Cereals Blend}

Low-cost, high-protein food product development for infants is a constant challenge. This is particularly important in developing countries where malnutrition problems are still common, particularly during weaning. Complementary foods in most developing countries are based on staple cereal or root crops and, commercial foods of high quality are occasionally available, they are often expensive and therefore un affordable by low-income rural households; thus, different approaches are needed to offer families the opportunity to feed their infants on improved formulations using low cost and locally available staples [5]. In a same research conducted to improve the protein and energy intake of infants in Iringa region, Tanzania, nine complementary foods were formulated (F1-F9) based on maize, sorghum and finger millet as staples and common beans, cowpeas and green peas as protein supplements that the samples were germinated and spatially roasted for the purpose of improving the nutritive value and sensory attribute of formulated recipes where all the formulations were evaluated for their sensory acceptability by both semiand untrained panelists using a five point hedonic scale. Complementary feeding improvement should be of highest priority for nutrition of infant and young children because of its crucial role in preventing mortality and enhancing children development Over $70 \%$ of dietary protein in developing countries is supplied by cereals that are relatively poor sources of protein [6]. Chemical Composition of Teff The chemical composition of cereals varies widely and depends on the environmental conditions, soil, variety and fertilizer. The importance of teff is mainly due to the fact that it has attractive nutritional profile and has no gluten found in other common cereals such as wheat, barley and rye. Now days the demand for gluten-free foods is growing among the people are which diagnosed with celiac disease and other types of gluten sensitivity [7].

\subsubsection{Fermentation and Fermentation Kinetics}

According to WHO food safety unit, fermentation is considered as a technique for preparation/storage of food. One main reason for this is that in developing countries, one tenth of the children under five years of age dies due to dehydration [8]. The dehydration is mainly caused by incidences of diarrhea. The main cause for getting diarrhea is the ingestion of food not having the appropriate standard regarding the hygienic condition. The hygienic standard of a food is based on the processing and handling of the food, as well as on the conditions of the raw materials. A food item prepared from water contaminated with pathogenic microorganisms will successively be contaminated, and a health risk. Lactic acid fermentation of food has been found to reduce the risk of having pathogenic microorganisms grow in the food.

Fermentation due to micro-organisms such as lactic acid bacteria has a significant effect on the growth of pathogenic micro-organisms [9]. Suggested that lactic acid bacteria are inhibitory to many other microorganisms when they are cultured together and this is the basis of the extended shelf life and improved microbiological safety of lactic-fermented foods. The microorganisms involved in fermentation of the Ethiopian pan cake, Injera, are mainly yeasts, some fungi species including Pullaria, Aspergillus, Penicillium, Rhodotorula, Hormodendrum, Candida and a number of unidentified bacteria [10-11]. In addition to this lactobacillus species can produce a variety of metabolites, such as lactic and acetic acids which lower the $\mathrm{pH}$ of the growth environment, that are inhibitory to competing bacteria including psychrotrophic pathogens [8]. This effect could be due to a combination of many factors as shown below in Table 1 . 
Table 1. Metabolites of lactic acid bacteria which may be inhibitory to other pathogenic and food spoilage organisms [8].

\begin{tabular}{ll}
\hline Product & Main target organisms \\
\hline Organic acid & Putrefactive and gram negative bacteria, some Fungi \\
Lactic acid & Putrefactive bacteria, clostridia, some yeasts and some fungi \\
Acetic acid & Pathogens and spoilage organisms, especially in protein rich foods \\
Hydrogen peroxide & \\
Enzymes & Pathogens and spoilage bacteria (milk and dairy products) \\
Lactoperoxidase system with hydrogen Peroxide & Undesired gram-positive bacteria \\
Lysozyme (by recombinant DNA) & \\
Low molecular weight metabolites & Wide spectrum of bacteria, yeasts and molds \\
Reuterin & Gram negative bacteria \\
$\begin{array}{l}\text { Diacetyl } \\
\text { Fatty acids }\end{array}$ & Different bacteria \\
Bacteriocins & \\
Nisin & Some LAB and gram-positive bacteria, notably endo-spore formers \\
Other & Gram positive bacteria, inhibitory spectrum according to producer strain and bacteriocin type \\
\hline
\end{tabular}

The inhibition by organic acids has been attributed to the protonated form of these acids, which are uncharged and may therefore cross biological membranes. The resulting inhibition of growth may be due to acidification of the cytoplasm and/or accumulation of anions inside the cell [9, $11,8]$.

Fermentation can activate several endogenous enzymes including phytases and may thus result in products with reduced anti-nutritional factors [12]. The extent to which enzymes like phytases are activated depends on the fermentation kinetics, which in turn, depends on the raw materials used [13]. Thus fermentation has beneficial effect in improving the nutritional and sanitary quality of food [14, $15]$.

The effect of fermentation on the protein and amino acids levels is a topic of controversy. For example, during the fermentation of corn meal the concentrations of available lysine, methionine, and tryptophan increase [16]. In the same way, fermentation significantly improves the protein quality as well as the level of lysine in maize, millet, sorghum, and other cereals [17]. On the contrary, investigations of the nutritive value of sorghum kisra bread showed no increase in the lysine content, although tyrosine and methionine levels did increase [18]. In the same line, it has been reported that the tryptophan content increases during Uji manufacture while a significant drop in lysine content was measured [18]. It appears that the effect of fermentation on the nutritive value of foods is variable, although the evidence for improvements is substantial. With regard to carbohydrate, natural fermentation of cereals leads to a decrease in the level of carbohydrates as well as some non digestible poly and oligosaccharides [19]

\subsubsection{Foods Based on Fermented Cereals}

A number of cereal based fermented foods exist in Africa including Kenkey in Ghana, togwa in Tanzania, mawe in Benin and ben-saalga in Burkina Faso [20, 21, 14]. In Ethiopia, Injera is the most common and popular fermented food from cereals such as teff, sorghum, maize, millet, and barley. Injera (Enjera) is the undisputed national food of Ethiopians [22-23]. Out of these cereals, teff (Eragrostis teff) is the major cereal ingredient in Ethiopian Injera [19] reported that sorghum ranks second to teff in preference for making Injera [24]. This could be due to the relative brittleness and dryness of sorghum Injera after storage [25]. However due to the high cost of fertilizer, engagement of intense labor for cultivation, weeding and harvesting, and the losses during harvesting, the price of teff is generally high as compared to sorghum and maize so that blending and compositing on the base teff is common in making Injera in spite of the fact that teff has an excellent nutritional value [26].

The nutritional composition of the above mentioned cereals is high which suggests that foods prepared from such cereals can also be nutritious particularly in terms of protein, energy, fat and amino acid content [20]. When teff is compared with other cereals, it has the highest content of lysine and other essential amino acids. In addition teff is also rich in starch but in terms of energy, it is slightly lower which is advantageous to diabetic type II patients. It has also high fiber content. In terms of micronutrient content teff is rich in Iron, Calcium and Zinc [27]. Considering phytate, polyhenol and tannin content, these cereals are rich in it with content variation among them. These phythochemicals are important as an antioxidant [27]. At the same time they are also inhibitory to the micronutrients obtained from those cereals. But fermentation and cooking can improve the inhibitory effect of the phythochemicals [8].

\subsubsection{Cereals Commonly Used in Teff Based Fermented Food Preparation}

i. Sorghum

It is believed that sorghum originated in Africa, more precisely in Ethiopia, between 5000 and 7000 years ago [28]. From there, it was distributed along the trade and shipping routes around the African continent, and through the Middle East to India at least 3000 years ago. It then journeyed along the Silk Route into China. Sorghum was first taken to North America in the 1700-1800's through the slave trade from West Africa. It was re-introduced in

Africa in the late 19th century for commercial cultivation and spread to South America and Australia. Sorghum is now widely found in the dry areas of Africa, Asia (India and China), the Americas and Australia [29]. According to FAO 
STAT among the major staple foods based on cassava, maize, yam, plantains, rice, wheat, millet, sweat potato, and bananas; sorghum occupies a unique position due to its hardiness as a crop [30]. Sorghum is drought-tolerant and resistant to water-logging [31] and grows in various soil conditions [32] and, also grows in temperate \& arid climate [33]. These characteristics contribute toward it being the staple crop of Africa's most food-insecure people, who live in the desert-margin, semiarid tropics of about 300 million people [31]. Like maize, sorghum does not have a true hull or husk [34]. Because of its similarity to maize (hard and floury endosperm that are large fat-rich germ), sorghum can be processed using technologies of dry and wet milling applied to maize [34]. The recent elucidation of the genome sequence will enhance future production and nutritional quality of sorghum [29]. Starch is the main component of sorghum grain, followed by proteins, non-starch polysaccharides (NSP) and fat. The average energetic value of whole sorghum grain flour is $356 \mathrm{kcal} / 100 \mathrm{~g}$ [35]. Sorghum has a macromolecular composition similar to that of maize and wheat [35]. However, sorghum contains resistant starch, which impairs its digestibility, notably for infants [36]. This resistance is desired in other applications to fight human obesity and to feed diabetic people. Foods prepared from high tannin sorghum varieties have a longer passage in the stomach [37]. Edible products incorporating slowly digestible starch are known to exhibit a low glycemic index and increase satiety [38].

ii. Wheat

The kernel of wheat is composed of the outer bran layer, the germ, and the endosperm. It is rich in nutrients, many of which are concentrated in the bran and germ. Of special importance is that it contains the entire B complex, except for vitamin B12. B vitamins function as cofactors in many metabolic reactions involved in the release of energy [39]. The germ, which includes the scutellum, is especially rich in vitamins $\mathrm{B}$ and $\mathrm{E}$, high quality protein, unsaturated fats, minerals, and carbohydrates. The bran consists mostly of the insoluble carbohydrate cellulose, and contains incomplete protein, traces of B vitamins, and minerals-especially iron. The endosperm is the largest part of the grain, and consists mostly of the carbohydrate starch, incomplete protein, and trace amounts of vitamins and minerals [40].

\section{iii. Maize}

Corn (Zea mays), also known as maize, is one of the world's leading cereal grains along with rice and wheat. In 2008 over 750 million metric tons were produced, with the United States, the European Union, China, Brazil, Mexico, and India being the world's leading producers [41]. Its popularity as a crop is largely due to its diverse functionality as a food source for both humans and animals. Kernels can be consumed off the cob, parched, boiled, fried, roasted, ground, and fermented for use in breads, porridges, gruel, cakes, and alcoholic beverages. Further processing leads to its use as food thickeners, sweeteners, oils, and nonconsumables [42-44]. Maize, providing an estimated $15 \%$ of the world's protein and $20 \%$ of the world's calories [45], is a dietary staple for more than 200 million people. This number can be expected to grow as the world's population approaches 8 billion in 2025 [46-47] indicating maize's status as a paramount important crop in the context of global nutrition.

More than $80 \%$ of the world starch market originates from corn [48]. Corn starch is a valuable ingredient to the food industry, being widely used as a thickener, gelling agent, bulking agent and water retention agent [49]. Maize contains about $72 \%$ starch, $10 \%$ protein, and $4 \%$ lipid [43], supplying an energy density of about $365 \mathrm{kcal} / 100 \mathrm{~g}$ [50]. In common maize varieties, the percentage of insoluble fiber is generally $12 \%$, while soluble fiber is less than $2 \%$. Taken as a dietary supplement, maize fiber $(89 \%$ dietary fiber, $<0.5 \mathrm{kcal} / \mathrm{g})$, which improved serum lipid levels in individuals with hypercholesterolemia, is a low-calorie alternative to other high fiber lipid-lowering products like wheat bran $(49 \%$ dietary fiber, $2 \mathrm{kcal} / \mathrm{g}$ ) [51].

\section{Results}

\subsection{Physical Characteristics of Teff Grain}

Teff is probably the smallest cereal grain with an average length of $\sim 1 \mathrm{~mm} 13$. The minuteness of teff grains has nutritional and technological implications. For instance, as teff grains are difficult to decorticate so, wholegrain cereals helps to improve nutritional quality for consumers. The color of teff can vary from white (ivory) to dark brown (black) depending on the variety. In Ethiopia, three major categories can be identified: white (nech), red (quey) and mixed (sergegna). It is also common for wholesalers to further subdivide white teff into very white (magna) and white (nech). White teff generally grows only in the Ethiopian highlands and require relatively good growing conditions.

\subsection{Chemical Composition of Teff}

The chemical composition of cereals varies widely and depends on the environmental conditions, soil, variety and fertilizer. The importance of teff is mainly due to the fact that it has attractive nutritional profile and has no gluten found in other common cereals such as wheat barley and rye. Now days the demand for gluten-free foods is growing among the people are which diagnosed with celiac disease and other types of gluten sensitivity [7].

Table 2. Nutritional and Microelement Composition of Teff Grain.

\begin{tabular}{ll}
\hline Nutrients & Amount \\
\hline Crude protein $(\mathrm{g} / 100 \mathrm{~g})$ & 11.0 \\
Crude fat $(\mathrm{g} / 100 \mathrm{~g})$ & 2.5 \\
Moisture $(\mathrm{g} / 100 \mathrm{~g})$ & 10.5 \\
Ash $(\mathrm{g} / 100 \mathrm{~g})$ & 2.8 \\
Crude fibre $(\mathrm{g} / 100 \mathrm{~g})$ & 3.0 \\
Carbohydrate $(\mathrm{g} / 100 \mathrm{~g})$ & 70.2 \\
Calcium $(\mathrm{mg} / 100 \mathrm{~g})$ & 165.2 \\
Copper $(\mathrm{mg} / 100 \mathrm{~g})$ & 2.6 \\
Iron $(\mathrm{mg} / 100 \mathrm{~g})$ & 15.7 \\
\hline
\end{tabular}




\begin{tabular}{ll}
\hline Nutrients & Amount \\
\hline Magnesium $(\mathrm{mg} / 100 \mathrm{~g})$ & 181.0 \\
Manganese $(\mathrm{mg} / 100 \mathrm{~g}$ & 3.8 \\
Phosphorus $(\mathrm{mg} / 100 \mathrm{~g})$ & 425.4 \\
Potassium & 380.0 \\
Sodium $(\mathrm{mg} / 100 \mathrm{~g})$ & 15.9 \\
Zinc $(\mathrm{mg} / 100 \mathrm{~g})$ & 4.8 \\
\hline
\end{tabular}

\subsection{Carbohydrates}

Carbohydrates are the major source of energy for humans and play an important role in metabolism and homeostasis. Based on the molecular size and degree of polymerization, carbohydrates can be classified into sugars, oligosaccharides, starch (amylose, amylopectin and non-starch polysaccharides) [52]. It's reported that complex carbohydrates make up 80 percent of teff grain. It has a starch content of approximately 73 percent making teff a starchy cereal. The amylose content of 13 teff varieties tested that ranged between 20 to 26 percent, comparable to other grains such as sorghum [53]. The carbohydrate content are found to be $73 \mathrm{~g} / 100 \mathrm{~g}$ in teff flour, which is similar to other cereal grains, such as white wheat flour- $75 \mathrm{~g} / 100 \mathrm{~g}$, rye flour$76 \mathrm{~g} / 100 \mathrm{~g}$ but lower than maize flour $(92 \mathrm{~g} / 100 \mathrm{~g})$ and higher than soya flour-(28g/100g) and brown wheat flour $(69 \mathrm{~g} / 100 \mathrm{~g})$ [54]. The difference in carbohydrate content in teff and other cereal grains flour could be explained by different levels of protein and fibre. Soya flour has high amount of protein $(37 \mathrm{~g} / 100 \mathrm{~g})$ and fibre $(11 \mathrm{~g} / 100 \mathrm{~g})$ as compared to teff flour [55]. White wheat flour has lower fibre content than brown wheat flour. Therefore, white wheat flour has similar carbohydrate amount as teff flour. Lower Glycemic Index of teff may be explained by its amylose content, lower starch damage, and the possible formation of amylose-lipid complexes that can hinder the enzymatic access and starch digestibility [56]. In addition, the high (68$80^{\circ} \mathrm{C}$ ) gelatinization temperature of teff $[52,56]$ can hinder the gelatinization and decrease susceptibility to enzymatic attack by $\alpha$-amylase [57].

\subsection{Protein}

The average crude protein content of teff is in the range of 8 to 11 percent, similar to wheat. Teff's fractional protein composition suggests that glutelins (45 percent) and albumins (37 percent) are the major protein storages while prolamins are a minor constituent ( 12 percent) [58]. In contrast, more recent studies reported that prolamins are the major protein storages in teff. By examining, the profile of amino acid in teff contains higher amount of glutamine, alanine, leucine and proline as compare to lysine [59]. Teff's amino acid composition is well-balanced as shown in Table 6. A relatively high concentration of lysine amino acid is found in teff. Similarly, compared to other cereals, higher contents of isoleucine, leucine, valine, tyrosine, threonine, methionine, phenylalanine, arginine, alanine and histidine are found in teff.

\subsection{Fat}

Cereals are not the best source of fat but as they are consumed in large quantities. It can contribute a significant amount of essential fatty acids to the diet [60]. The crude fat content of

teff is higher than that of wheat and rice, but lower than maize and sorghum (Table 6). Rice, wheat and maize contains negligible amount of linoleic acid (LA) and traces of $\alpha$-linoleic acid (ALA). Furthermore, these widespread cereals are consumed after decortications and further refining which reduces their amount of crude fat and poly-unsaturated fatty acids. Teff grains are rich in unsaturated fatty acids, predominantly oleic acid (32.4\%) and linoleic acids (23.8\%) [61].

\subsection{Crude Fiber}

The crude fibre content in teff $(3.0 \mathrm{~g} / 100 \mathrm{~g})$ is far higher than the other gluten containing and gluten-free cereals.

Consumption of dietary fiber provides many health benefits.

The dietary fiber content of teff $(8.0 \mathrm{~g} / 100 \mathrm{~g})$ is high when compared to some fruits, nuts, pulses and cereals such as corn and rice [62]. Studies revealed that high fiber diets prevent many human diseases like colon cancer, coronary heart disease and diabetes [63].

Table 3. Macro, amino acid composition of teff [56, 60].

\begin{tabular}{ll}
\hline Amino acid (g/16 $\mathbf{g} \mathbf{~})$ & Teff \\
\hline Lysine & 3.7 \\
Isoleucine & 4.1 \\
Leucine & 8.5 \\
Valine & 5.5 \\
Phenylalanine & 5.7 \\
Tyrosine & 3.8 \\
Tryptophan & 1.3 \\
Threonine & 4.3 \\
Histidine & 3.2 \\
Arginine & 5.2 \\
Methionine & 4.1 \\
Cystine & 2.5 \\
Asparagine & 6.4 \\
Serine & 4.1 \\
Glutamine + Glutamic Acid & 21.8 \\
Proline & 8.2 \\
Glycine & 3.1 \\
Alanine & 10.1 \\
\hline
\end{tabular}

\subsection{Minerals}

The difference in mineral content between and within teff varieties is wide ranging. Red teff has a higher iron and calcium content than mixed or white teff. On the other hand, white teff has a higher copper content than red and mixed teff (Table 4). The most recent study investigated iron content in selected teff grains. Their findings showed that teff contained almost $38 \mathrm{mg} / 100 \mathrm{~g}$ and more than $150 \mathrm{mg} / 100 \mathrm{~g}$ of iron in locally purchased white and red teff grains varieties respectively [28]. 
Table 4. Mineral content of teff grain [64, 65].

\begin{tabular}{llll}
\hline Minerals (mg/100 g) & White teff & Red teff & Mixed teff \\
\hline Iron & $9.5-37.7$ & $11.6->150$ & $11.5->150$ \\
Zinc & $2.4-6.8$ & $2.3-6.7$ & $3.8-3.9$ \\
Calcium & $17-124$ & $18-178$ & $78.8-147$ \\
Copper & $2.5-5.3$ & $1.1-3.6$ & 1.6 \\
\hline
\end{tabular}

Teff has a higher iron, calcium and copper content than other common cereals. The zinc content of teff is also higher than that of sorghum and wheat. The zinc content of teff grains reported by the researchers varies from $2.00 \mathrm{mg} / 100 \mathrm{~g}$ to $6.77 \mathrm{mg} / 100 \mathrm{~g}$. The zinc content of teff is similar to other cereal grains, such as barley, wheat and maize [53]. However, the high iron content of teff has been contested and in many instances attributed to soil contaminations [28]. Recently examined the content of iron, zinc and calcium in teff, barley, wheat, and sorghum before and after washing with de-ionized water. Teff is notably higher in calcium than other cereals [64]. Teff grains contain between $147-180 \mathrm{mg} / 100 \mathrm{~g}$ of calcium whereas wheat grains contain $3.33 \mathrm{mg} / 100 \mathrm{~g}$ [53], barley-46mg/100g and maize- $16 \mathrm{mg} / 100 \mathrm{~g}$ of calcium [66].

The mineral contamination of teff is probably due to its small size and suggests increased contact with soil over a larger area. Recently compared the iron content of the same variety of teff after laboratory (manually) and traditional threshing [67]. Traditional threshing leads to 30 to 38 percent increase in iron content due to soil contamination. Teff is still a better source of iron than other cereals like wheat, barley, sorghum, and maize. In contrast to iron showed that under the same conditions, the values reported for calcium and zinc are consistent and are less affected by washing [64]. This suggests that soil contamination contributes little to the content of these minerals in teff.

\subsection{Total Phenol Compounds}

The other most important health-promoting aspects of teff as a food is like other millets. It is generally assumed to contain substantial amounts of phenolics [68]. Research findings revealed that ferulic acid $(285.9 \mu \mathrm{g} / \mathrm{g})$ is the major phenolic compound in teff. Some other phenolic compounds such as protocatechuic $(25.5 \mu \mathrm{g} / \mathrm{g})$, gentisic $(15 \mu \mathrm{g} / \mathrm{g})$, vanillic $(54.8 \mu \mathrm{g} / \mathrm{g})$, syringic $(14.9 \mu \mathrm{g} / \mathrm{g})$, coumaric (36.9 $\mu \mathrm{g} / \mathrm{g})$, and cinnamic $(46 \mu \mathrm{g} / \mathrm{g})$ acids are also present in teff in considerable amounts [69]. Phenolics are notable for their antioxidant activity which appears to be beneficial in terms of prevention of cardiovascular diseases and cancer [70]. They also act as natural antioxidants for the food industry. At the same time, they might inhibit digestive enzymes and reduce food digestibility [71].

Table 5. Phytochemical composition of teff grain [28, 64].

\begin{tabular}{ll}
\hline Phytate (mg/100 g dry matter) & $682-1374$ \\
Tannin (mg CE/100 g dry matter) & 16 \\
Total polyphenols (mg gallic acid equivalent/100 g dry & 140 \\
matter) & \\
Ironbindingphenolics & \\
Galloyls (mg tannic acid equivalent/100 g dry matter) & 210 \\
Galloyls (mg tannic acid equivalent/100 g dry matter) & 200 \\
Phenolic acids $(\mu \mathrm{g} / \mathrm{mg})$ & \\
Protocatechuic & 25.5 \\
Gentisic & 15 \\
$p$-0OH Benzoic & - \\
Vanillic & 54.8 \\
Caffeic & 3.9 \\
Syringic Ferulic & 14.9 \\
Ferulic & 285.9 \\
Cinnamic & 46 \\
\hline
\end{tabular}

\subsection{Relationship Between Nutrient Composition of Teff and Common Cereal Crops}

The nutritive composition of teff and common cereals used in the fermented products such as injera (table 6).

Table 6. Macro, amino acid and fatty acid composition of teff grain compared to maize, sorghum, wheat and rice [72].

\begin{tabular}{|c|c|c|c|c|c|}
\hline Nutrient & Teff & Maize & Sorghum & Wheat & Rice \\
\hline Energy (Kcal) & 357 & 375 & 370 & 359 & 357 \\
\hline Starch $(\%)$ & 73 & 72 & 63 & 71 & 64 \\
\hline Crude protein $(\%)$ & 11 & $8-11$ & 8.3 & 11.7 & 7.3 \\
\hline \multicolumn{6}{|l|}{ Amino acid $(\mathrm{g} / 16 \mathrm{gN})$} \\
\hline Lysine & 3.7 & 0.3 & 2.1 & 3.7 & 3.7 \\
\hline Isoleucine & 4.1 & 0.7 & 3.7 & 4.5 & 4.1 \\
\hline Leucine & 8.5 & 2.1 & 7.0 & 8.2 & 8.5 \\
\hline Valine & 5.5 & 0.8 & 4.1 & 6.0 & 5.5 \\
\hline Phenyl alanine & 5.7 & 0.9 & 4.9 & 5.5 & 5.7 \\
\hline Tyrosine & 3.8 & 0.7 & 2.3 & 5.2 & 3.8 \\
\hline Typtophan & 1.3 & 0.2 & 1.1 & 1.2 & 1.3 \\
\hline Threonine & 4.3 & & 0.5 & 2.7 & 3.7 \\
\hline Histidine & 3.2 & & 0.4 & 2.1 & 2.3 \\
\hline Arginine & 5.2 & & 0.6 & 3.5 & 8.5 \\
\hline Methionine & 5.2 & & 0.6 & 3.5 & 8.5 \\
\hline Cystine & 2.5 & & 0.3 & 2.4 & 1.8 \\
\hline Asparagines & 6.4 & & & 5.1 & 9.0 \\
\hline Serine & 4.1 & & 0.8 & 5.0 & 5.0 \\
\hline Glutamine + glutamicAcid & 21.8 & & & 29.5 & 17.0 \\
\hline Proline & 8.2 & & 1.3 & 10.2 & 5.0 \\
\hline Glycine & 3.1 & & 0.5 & 4.0 & 4.5 \\
\hline Alanine & 10.1 & & 1.6 & 3.6 & 5.5 \\
\hline
\end{tabular}




\begin{tabular}{llllll}
\hline Nutrient & Teff & Maize & Sorghum & Wheat & Rice \\
\hline Crude fat (\%) & 2.5 & 4.9 & 3.9 & 2 & 2.2 \\
Total unsaturated fattyAcid & 1.1 & 1.8 & 1.4 & 0.5 & 0.8 \\
Linoleic acid (LA) & 0.9 & 1.7 & 1.3 & 0.5 & 0.78 \\
a-linoleic acid (ALA) & 0.14 & 0.05 & 0.07 & 0.03 & 0.03 \\
LA: ALA ratio & $7: 1$ & $34: 1$ & $20: 1$ & $17: 1$ & $26: 1$ \\
Crude fiber (\%) & 3.0 & - & 0.6 & 2.0 & $0.6-1.0$ \\
Total dietary fiber & 4.5 & 2.6 & & & - \\
Soluble dietary fiber & 0.9 & 0.6 & 1.6 & & - \\
Ash (\%) & 2.8 & 1.4 & & & 1.6 \\
\hline
\end{tabular}

\section{Discussion}

Over the past decade, the recognition that teff is glutenfree has raised global interest. The existing literature suggests that teff is composed of complex carbohydrates with slowly digestible starch. Teff has similar protein content to other more common cereals like wheat, but is relatively richer than other cereals in the essential amino acid, lysine. Teff is also a good source of essential fatty acids, fiber, minerals (especially calcium and iron) and phytochemicals (polyphenols and phytates). Existing studies of the nutrition and health benefits of teff are limited since they fail to take into account difference in teff varieties and growing conditions. Nevertheless, the studies undertaken so far confirms teff's excellent nutrient profile and suggests that it has considerable potential globally to be a functional food for health promotion and disease prevention. However, in the past decade, studies on the nutritional composition of teff and its processing quality and development of new teff-based food products have grown. These studies have confirmed the excellent nutrient composition of teff and demonstrated that through the use of enzymes, hydrocolloids, or sourdough fermentation that it may be possible to overcome food processing challenges faced when using teff as an ingredient for bread making. Further research should investigate the variation in nutrient composition across teff varieties, the role of teff consumption on the management and prevention of diabetes, and the human adsorption (bioavailability) of iron in teff and how it can contribute to the prevention of iron deficiency. Along with the possible health benefits in managing celiac disease, and a possible solution in preventing and controlling iron deficiency and diabetes, these all indicate the potential of teff to be a future global functional food for health promotion and disease prevention.

\section{Conclusion}

Teff has an excellent nutritional profile and also a gluten free cereal. In connection to its medicinal values interests are growing in many countries to utilize teff for the production of gluten free foods. It is a tropical low risk grain that grows in a wider ecology and can tolerate harsh environmental conditions where most other cereals are less feasible. Thus, it has the potential of growing in every part of the world. Teff has an excellent balance of essential amino acids and is a good source of calcium and iron, which may explain the low occurrence of anemia in areas of Ethiopia where to regular teff consumption. Hence, Teff is an ideal and healthy ingredient for many gluten-free recipes. A thorough knowledge of the environment of the target production region is critical, as this determines yield potential, the range and type of challenges the crop will experience from biological threats such as pests and diseases and soil and environmental stresses.

\section{Conflict of Interest}

The authors declare that they have no conflict of interest.

\section{References}

[1] Spaenij-Dekking L, Kooy-Winkelaar Y, Koning F. The Ethiopian Cereal Teff in Celiac Disease. N Engl J Med. 2005; 353 (16): 1748-1749.

[2] Baye, K., Claire, M. R., Christèle, I. V., Isabelle, R., JeanPierre, G.(2012) Influence of flour blend composition on fermentation kinetics and phytate hydrolysis of sourdough used to make injera, ELSEVIER Journal of food chemistry, 1.

[3] Bultosa, G., Hall, A. N. and Taylor, J. R. N. (2002) 'Physicochemical characterization of grain tef [Eragrostis tef (Zucc.) Trotter] starch'. Starch-Starke, Vol. 54, Issue 10, pp. 461-468.

[4] Bultosa, G. (2007). Physicochemical Characteristics of Grain and Flour in 13 Tef [Eragrostis tef (Zucc.) Trotter] Grain Varietis'. Journal of Applied Science Research, Vol. 3, Issue 12, pp. 2042-2051.

[5] Happiness, S., Muhimbula, Abdulsudi, I. Z. and Joyce, K. (2011); Formulation and sensory evaluation of complementary foods from local, cheap and readily available cereals and legumes in Iringa, Tanzania; African Journal of Food Science Vol. 5 (1), pp. 26-31.

[6] Glover, D. V. (1976). Improvement of protein quality in maize. In: Wilke HL, ed. Improving the nutrient quality of cereals. Washington, DC: AID pp. 69-97.

[7] Hopman E, Dekking L, Wuisman ML et al. Teff in the diet of celiac patients in the Netherlands. Scand J Gastroenterol. 2008; 43 (3): 277-282.

[8] Peter Sahlin (1999); Fermentation as a Method of Food Processing, production of organic acid $\mathrm{PH}$ development and microbial growth in fermenting cereals; Lund Institute of Technology; Licentiate thesis, pp. 11-22.

[9] Adams, M. R. (1990). Topical aspects of fermented foods. Trends in Food Science \& Technology 1: 141-144. 
[10] Ashenafi, M. (1993). Ethiopian enjera. In K. H. Steinkraus (Ed.), Handbook of indigenous fermented foods New York, Marcel Dekker. pp. 182-194.

[11] Steinkraus, K. H. (1983). Fermented foods, feeds and beverages. Biotechnology Advances, 10, 31-46.

[12] Greiner, R., and Konietzny, U. (2006). Phytase for Food Application. Food Technology and Biotechnology, 44 (2), $125-140$.

[13] Hammes, W. P., Brandt, M. J., Francis, K. L., Rosenheim, J., Seitter, M. F. H., \& Vogelmann, S. A. (2005). Microbial ecology of cereal fermentations. Trends in Food Science \& Technology, 16 (1-3), 4-11.

[14] Nout, M. J. R. (2009). Rich nutrition from the poorest Cereal fermentations in Africa and Asia. Food Microbiology, 26 (7), 685-692.

[15] Svanberg, U., \& Lorri, W. (1997). Fermentation and nutrient availability. Food Control, 8 (5-6), 319-327.

[16] Nanson, N. J., \& Field, M. L. (1984). Influence of temperature on the nutritive value of lactic acid fermented cornmeal. Journal of Food Science, 49, 958-959.

[17] Hamad, A. M., \& Fields, M. L. (1979). Evaluation of protein quality and available lysine of germinated and ungerminated cereals. Journalof Food Science, 44, 456-459.

[18] McKay, L. L., \& Baldwin, K. A. (1990). Applications for biotechnology: present and future improvements in lactic acid bacteria. FEMS Microbiology Reviews, 87, 3-14.

[19] Blandino, A., Al-Aseeri, M. E., Pandiella, S. S., Cantero, D., and Webb C. (2002). Cereal-based fermented foods and beverages, Food research international, ELSEVIER, 528530 .

[20] Baye, K. (2014), Teff: Nutrient Composition and Health Benefit; Ethiopia, strategy support program; Ethiopian Development Research Institute; International Food Policy Research Institute, Working Paper (67), 1-6.

[21] Guyot, J. P. (2010). Fermented cereal products. In J. P. Tamang (Ed.), Fermented foods and beverages of the world, Boca Raton, London, New York: CRC Press (Taylor and Francis Group). pp. 247-261.

[22] Chavan, J. K., \& Kadam, S. S. (1989). Critical reviews in food science and nutrition. Food Science, 28, 348-400.

[23] Oda, M., Hasegawa, H., Komatsu, S., Jambe, M., \& Tsuchiya, F.(1983). Antitumour polysaccharide from Lactobacillus sp. Agricultural and Biological Chemistry, 47, 1623-1625.

[24] Kebede, Y., Menkir, A. (1984). Research activities of the Ethiopian sorghum improvement programme. In Proceeding of the Third Workshop on Sorghum and Millet Improvement in Eastern Africa Morogoro, Tanzania. pp. 73-97.

[25] Zegeye, A. (1997). Acceptability if Injera with stewed chicken. Food Quality and Preference, 8: 293-295.

[26] Bekabil, F., Befekadu, B., Rupert, S. and Tareke, B. (2011). Strengthening the teff valu.

[27] Abebe Y, Bogale A, Hambidge KM et al. Phytate, Zinc, Iron and Calcium Content of Selected Raw and Prepared Foods Consumed in Rural Sidama, Southern Ethiopia, and Implications for Bioavailability. J Food Compos Anal. 2007;
20 (3): 161-168.

[28] ICRISAT (2005). Sorghum report. Patancheru India.

[29] ICRISAT (2009). Sorghum. http://test1.icrisat.org/New\&Events/Genome.htm Accessed June 2014.

[30] FAO, (2008). Food Security Statistics, Food Consumption, Dietary Energy, Proteins, Fat. www.fao.org/economic/ess/foodsecurity-statistics/en/ Accessed January 2015.

[31] Doggett, H. (1988). Sorghum, 2nd ed. Longman Scientific and Technical, London, pp 1-3.

[32] Dillon, S. L., Shapter, F. M., Henry R. J., Cordeiro, G., Izquierdo, L., and Lee, L. S. (2007). Domestication to Crop Improvement: Genetic Resources for Sorghum and Saccharum (Andropogoneae). Annals of Botany 100 (5): 975-989.

[33] Lloyd, R., Scott, B., Nancy, T., Mark, H., Jeff, D., Curt, W., Joseph, A., and Virgil, S. (2010). Sorghum: An Ancient, Healthy and Nutritious Old World Cereal, pp 3-4.

[34] Taylor, J., K., N., (2003). Overview: Importance of sorghum in Africa. In: Afripro: Workshop on the Proteins of Sorghum and Millets: Enhancing Nutritional and Function Properties for Africa. Eds. P. S. Belton and J. R. N. Taylor. Pretoria, 204 April, 2003, Paper, 01.

[35] BSTID-NRC (1996). Board on Science and Technology for International Development-National Research Council.

[36] FAO, (1995). Sorghum and millet in human nutrition. Food and Agricultural Organization, Food and Nutrition Series No. 27. ISBN 92-5-103381-1.

[37] Awika, J. M., and Rooney, L. W. (2004). Sorghum phytochemicals and their potential aspects on human health. Phytochemistry. 65: 1199-1221h.

[38] Shin SI, Choi HJ, Chung KM, Hamaker BR, Park KH, Moon TW (2004). Slowly digestible starch from debranched waxy sorghum starch: Preparation and properties. Cereal Chem. 81: 404408 .

[39] Birdsall, "Summary and Areas for Future Research." Am. J. of Clin. Nutr. 41 (5 suppl) May 1985: 1172-1176.

[40] Guthrie, Helen A. Introductory Nutrition. Missouri: Times Mirror/ Mosby College Publishing, 1989. Hall, Ross Hume. Food for Nought-The Decline in Nutrition. Maryland: Harper \& Row, 1974. (Chapter: Lifeless Bread).

[41] USDA/FAS (United States Department of Agriculture and Foreign Agricultural Service). (2008). Corn2008: production, supply, demand database. Available from: http://www.pecad.fas.usda.gov/cropexplorer/. Accessed Nov2014.

[42] Alexander, R. J. (1987). Corn dry milling: processes, products, and applications. In: Watson SA, Ramstad PE, editors. Corn: chemistry and technology. St. Paul, Minn.: Am Assoc Cereal Chem. pp. 351-76.

[43] Gardner, H. W. and Inglett, G. E. (1971). Food products from corn germ: enzyme activity and oil stability. J Food Sci 36: $645-8$. 
[44] Whistler RL. (1970). Industrial uses of corn starches. In: Inglett GE, editor. Corn: culture, processing, products. Westport, Conn.: Avi Publishing. p 171-94.

[45] Brown, W. L., Zuber, M. S., Darrah, L. L. and Glover, D. V. (1985). Origin, adaptation, and types of corn, Iowa State Extension, Ames, IA: National Corn Handbook. Available at http://corn.agronomy.wisc.edu/Management/pdfs/NCH10.pdf (accessed December, 2014).

[46] Lutz, W., Sanderson, W., and Scherbov, S. (2001). The end of world population growth. Nature 412: 543-5.

[47] USDA (United States Department of Agriculture). (2009a). World agricultural production: world wheat area down, corn steady, soy up. Foreign Agricultural Service/USDA Office of Global Analysis. p 1-7. Available from: http://www.fas.usda.gov/wap/circular/2009/09-05/ productionfull05-09.pdf. Accessed Nov 2014.

[48] Jobling, S. (2004) Plant Biotech, 7, 210.

[49] Singh, N., Singh, J., Kaur, L., Sodhi, N. S. and Gill, B. S. (2003). Food Chemistry, 81: 219.

[50] USDA (United States Department of Agriculture). (2009b). National nutrient database for standard reference. Available from: http://www.nal.usda.gov/fnic/foodcomp/search/. Accessed Sept and Oct 2014.

[51] Earll, L., Earll, J. M., Naujokaitis, S., Pyle, S., McFalls, K. and Altschul, A. M. (1988).

[52] Bultosa G. Physicochemical Characteristics of Grain and Flour in 13 Teff [Eragrostis tef (Zucc.) Trotter] Grain Varieties. J Appl Sci Res. 2007; 3 (12): 2042-2051.

[53] USDA. National Nutrient Database for Standard Reference Release 20, [online]. 2007 [cited 2007 Sept 5].

[54] National Research Council 'Lost Crops of Africa' Grains. National Academy Press: Washington DC. 1996; (1): 215534.

[55] McCance RA, Widdowson EM. The Composition of Foods. 6th ed. Royal Society of Chemistry: Cambridge, 2002.

[56] Wolter A, Hager AS, Zannini $E$ et al. In vitro starch digestibility and predicted glycaemic indexes of buckwheat, oat, quinoa, sorghum, teff and commercial gluten-free bread. J Cereal Sci. 2013; 58 (3): 431-436.

[57] Fardet A, Leenhardt F, Lioger D et al. Parameters controlling the glycaemic response to breads. Nutr Res Rev. 2006; 19 (1): 18-25.

[58] Tatham AS, Fido RJ, Moore CM et al. Characterisation of the major Prolamins of teff (Eragrostis Tef) and finger millet (Eleusine Coracana). J Cereal Sci. 1996; 24 (1): 6571.

[59] Adebowale ARA, Emmambux MN, Beukes $M$ et al.
Fractionation and characterization of teff proteins. J Cereal Sci. 2011; 54 (3): 380-386.

[60] Michaelsen KF, Dewey KG, Perez- Exposito AB et al. Food sources and intake of n- 6 and n- 3 fatty acids in lowincome countries with emphasis on infants, young children (6-24 months), and pregnant and lactating Women. Matern Child Nutr. 2011; 7 (2): 124-140.

[61] EI-Alfy TS, Ezzat SM, Sleem AA. Chemical and biological study of the seeds of Eragrostis tef (Zucc.) Trotter. Nat Prod Res. 2012; 26 (7): 619-629.

[62] Saturni L, Ferretti G, Bacchetti T. The gluten-free diet: Safety and nutritional quality. Nutr. 2010; 2 (1): 16-34.

[63] Anderson JW, Baird P, Davis RH et al. Health benefits of dietary fiber. Nutr Rev. 2009; 67 (4): 188-205.

[64] Baye K, Mouquet-Rivier C, Icard-Vernière CE et al. Changes in mineral absorption inhibitors consequent to fermentation of Ethiopian injera: Implications for predicted iron bioavailability and bioaccessibility. Int J Food Sci Technol. 2014; 49 (1): 174-180.

[65] Kebede Z. Levels of Essential Elements in Three Teff [Eragrostis tef (Zucc.) Trotter] Varieties. Addis Ababa University, 2009.

[66] Mengesha MH. Chemical composition of teff (Eragrostis tef) compared with that of wheat, barley and grain sorghum. Econ Bot. 1996; 20 (3): 268-273.

[67] Ambaw A. Determination of Iron Fractions of Laboratory Threshed and Field Threshed Teff Injera. Addis Ababa University, 2013.

[68] Dykes L, Rooney LW. Phenolic Compounds in Cereal Grains and Their Health Benefits. Cereal Foods World. 2007; 52 (3): $105-111$.

[69] McDonough CM, Rooney LW. The millets. In: Kulp K and Ponte JG. (eds.) Handbook of cereal science and technology. Marcel Dekker: New York, 2000, 177-201.

[70] Awika JM, Rooney LW. Sorghum phytochemicals and their potential impact on human health: review. Phyto chem. 2004; 65: 1199-1221.

[71] Maheshu V, Priyadarsini DT, Sasikumar JM. Effects of processing conditions on the stability of polyphenolic contents and antioxidant capacity of Dolichos lablab L. J Food Sci Technol. 2013; 50 (4): 731-738.

[72] Agren, G. and Rosalind S. G. (1968). Food Composition Table for Use in Ethiopia. Swedish International Development Authority, Stockholm, and Ethiopian Nutrition Institute, Addis Ababa. 